\title{
Transfusing our lifeblood: Reframing research impact through inter-disciplinary collaboration between health geography and nurse education
}

\author{
Richard G. Kyle ${ }^{\mathrm{a}, *}$, Iain M. Atherton ${ }^{\mathrm{a}}$, Mike Kesby ${ }^{\mathrm{b}}$, Matthew Sothern ${ }^{\mathrm{b}}$, Gavin Andrews ${ }^{\mathrm{c}}$ \\ a School of Nursing, Midwifery and Social Care, Edinburgh Napier University, UK \\ ${ }^{\mathrm{b}}$ Department of Geography and Sustainable Development, University of St Andrews, UK \\ ${ }^{c}$ Department of Health, Aging \& Society, McMaster University, Canada
}

\section{A R T I C L E I N F O}

Article history:

Received 2 February 2016

Received in revised form 22 June 2016

Accepted 2 August 2016

Available online $\mathrm{xxx}$

Keywords:

Research impact

Research assessment

Geography

Nursing

Interdisciplinary

Students

Pedagogy

\begin{abstract}
A B S T R A C T
Geographers have long grappled with how their research can positively impact individuals, communities and society. Demonstrating research impact is an increasingly important aspect of academic life internationally. In this paper we argue that agendas for encouraging 'impact' would be well-served if impact through teaching was identified and stimulated more explicitly, and if academics better recognised and seized the opportunities that already exist for such impact. We take engagement between health geography and nurse education as an example of how social scientists could demonstrate research impact through inter-disciplinary involvement in the education of health care professionals, and specifically student nurses. We begin by showing how the UK's Research Excellence Framework (widely regarded as the key reference point for research performance management regimes internationally) has tended to produce an undervaluation of impact via education in many disciplines. A comprehensive overview of international scholarship at the intersection between geography and nursing is then presented. Here we trace three 'waves of enquiry' that have focused on research interactions before calling for a fourth focused on critical pedagogy. To illustrate the possibilities of this fourth wave, we sketch a case study that outlines how engagement with research around blood donation could help provide a foundation for critical pedagogy that challenges student nurses to practice reflexively, think geographically and act justly. Finally, we call for closer engagement between health geography and nurse education, by encouraging educators to translate, teach, and transfuse ideas and people between health geography and nurse education. In so doing, we argue that work at this interface can be mutually beneficial and demonstrate impact both within and beyond research assessment rubrics. Hence, our ideas are relevant beyond nurse education and geography insofar as this paper serves as an example of how reframing research impact can recover the importance of impact through education.
\end{abstract}

(C) 2016 Published by Elsevier Ltd.

\section{Introduction}

Human geography both advances understanding of the world and is unapologetically applied. Yet, geographers have long grappled with the balance between its theoretical and practical edges. Internationally, these debates have been thrown into sharp relief through the need for academics to demonstrate the impact of their research on economy, society, culture, public policy or services, health, the environment or quality of life, beyond academia. Such 'impact' is measured through institutional audits such as the UK's Research Excellence Framework (REF), Excellence in Research for Australia (ERA), and New Zealand's Performance-based Research Fund (PBRF). Although renewed emphasis on the public benefit of (often publicly funded) academic work is welcome, such audits do not simply measure activities, they actively produce them. Arguably, they presently cause academics to focus primarily on having impact on policy, practice and (profitable) commercial enterprise, rather than to consider the impact they might make by cultivating critical enquiry and reflexive praxis among students, especially across disciplinary

\footnotetext{
* Corresponding author. School of Nursing, Midwifery and Social Work, Edinburgh Napier University, Sighthill Campus, EH11 4BN, UK

Email address: r.kyle@napier.ac.uk (R.G. Kyle)
}

borders. The resultant missed opportunity is very apparent in the general lack of proactive engagement between social science researchers and disciplines such as nurse education where students are training for careers delivering services and care to the public.

In this paper we argue that agendas for encouraging 'impact' would be well-served if impact through teaching was identified and stimulated more explicitly, but equally, that academics should better recognise and utilise the opportunities that already exist for such impact. We take engagement between health geography and nurse education as an example of how social scientists could demonstrate research impact through inter-disciplinary involvement in the education of health care professionals, and specifically student nurses. We begin by showing how the UK's REF exercise (widely regarded as the key reference point for research performance management regimes internationally) has tended to produce an undervaluation of impact via education in many disciplines. A comprehensive overview of international scholarship at the intersection between geography and nursing is then presented. Here we trace three 'waves of enquiry' that have focused on research interactions before calling for a fourth focused on critical pedagogy. To illustrate the possibilities of this fourth wave, we sketch a case study that outlines how engagement with critical research around blood donation could help provide a foundation for critical pedagogy that challenges student nurses to 
practice reflexively, think geographically and act justly. Finally, we call for closer engagement between health geography and nurse education, by encouraging educators to translate, teach, and transfuse ideas and people between health geography and nurse education. In so doing, we argue that work at this interface can be mutually beneficial and demonstrate impact both within and beyond research assessment rubrics. Hence, our ideas are relevant beyond nurse education and geography insofar as this paper serves as an example of how reframing research impact can recover the importance of impact through education.

\section{Research impact}

Debates about research impact are not new to geography. Geographers have long strived to ensure their research not only serves to better understand the lives of others, but enables change through direct engagement with participants or by providing evidence that shapes the policy process. Calls have been made repeatedly to demonstrate and defend geography's applied edge (see summary in Kyle et al., 2011). In recent years, these calls have been mounted as a challenge to the neo-liberalisation of higher education, which inter alia, the codification of research impact through performance management regimes such as the UK's REF signals (Pain et al., 2011).

Born of Margaret Thatcher's government in an era of fiscal restraint, the UK's first Research Selectivity Exercise was conducted in 1986 (King's College London, 2015). Its aim to assess research quality in order to allocate limited public funds across institutions has remained unchanged through subsequent incarnations of the exercise in 1989, 1992, 2001 and 2008, despite notable changes in the mechanisms of assessment, grading rubrics, and increases in the scope, scale and cost of the exercise over the intervening three decades. REF2014 represented a "step change" for the UK assessment exercise (Penfield et al., 2014) (and those that emulate it) by introducing the new measure of 'research impact'. This now counts for $20 \%$ of the overall weighting of assessment, adjusting downward the relative weighting of the existing measures of 'quality of published research outputs' and 'research environment' (now 65\% and 15\% respectively). In guidance issued to universities, research impact was defined as: "an effect on, change or benefit to the economy, society, culture, public policy or services, health, the environment or quality of life, beyond academia." (HEFCE, 2011; emphasis added).

Submitted impact case studies were assessed in terms of their 'reach' and 'significance' and scored between 1 and 4 stars, or were unclassified (HEFCE, 2011). Because of the novelty of 'research impact' in REF2014 and its likely increased prominence in REF2021 (HEFCE, 2011), impact case studies submitted to REF2014 have come under close scrutiny since publication of REF results (King's College London, 2015). Such inspection is an inevitable product of the neo-liberal project REF supports and much effort is being expended to understand the rules of the game so as to better enable the gaming known to plague such exercises (Martin, 2011). Yet, a critical post-positivist assessment of audit measures would suggest not only that they have already reshaped the academy, but that if reframed, they could remake it again in more productive ways.

Taking all 162 impact case studies submitted to the Public Health, Health Services Research and Primary Care Unit of Assessment (UoA 2), Greenhaugh and Fahy (2015) used content analysis followed by detailed qualitative enquiry to identify the most commonly cited research designs (i.e., randomised controlled trials), impacts (influenced new or revised guideline) and approaches to achieving im- pact (strong and on-going links with policy makers). Summing up their findings they noted that "the dearth of designs grounded in the social sciences $[\ldots]$ is consistent with previous claims that such work rarely produces direct and readily measurable impacts" (Greenhaugh and Fahy, 2015: 8), yet they are critical of the tendency to privilege direct (linear) links between research and impact over indirect effects.

Developing mindliness - defined as "collectively generated and socially shared tacit knowledge developed in professional communities of practice" (Greenhaugh and Fahy, 2015: 2) - is, they contend, a common route through which indirect impact occurs among health professionals. Education is essential to develop mindliness, yet the stress placed on 'impact' being defined as effects of research "beyond academia" (HEFCE, 2011; emphasis added) has tended to down-play the possibility of impact through teaching - even though this was admissible to the audit (where demonstrable beyond one's own students/ institution) (HEFCE, 2012). Data mining of all publically available impact case studies submitted to REF2014 confirmed the side-lining of educational impact, with just $2 \%$ of submitted case studies in both the nursing and geography units of assessment (UoA 3 and 17, respectively) citing educational impact (King's College London, 2015).

Addressing the "concern" that "researchers [placed] relatively low emphasis on the processes and interactions through which indirect impacts may occur" (Greenhaugh and Fahy, 2015: 1), this paper aims to recover education as a route through which research impact can be realised, both within and beyond research assessment rubrics. Specifically, it presents a case study of one pathway to educational impact by suggesting how ever-closer engagement between health geography and nurse education might encourage student nurses to embrace social science approaches and insights in ways that enhance the care they provide to their patients. In so doing, we propose a fourth wave of enquiry at the long-standing intersection between geography and nursing.

\section{Geography and nursing}

A loose chronology of the scholarly intersections between geography and nursing might identify three 'waves' of enquiry (see Andrews, 2016):

1. The 'nursing environment' as a meta-concept in nursing theory;

2. Environment as an empirical concern;

3. Geographies in nursing.

Below each is summarised, before we sketch a fourth 'wave': geography as a critical pedagogical approach.

\subsection{The first wave: the 'nursing environment' as a meta-concept in nursing theory}

A familiar story often re-told across academic literature and institutions is how environment is a main leitmotif in Florence Nightingale's famous Notes on Nursing (Nightingale, 1859). This important text made early observations on sanitary and housing circumstances in nineteenth century European cities, on the conditions, variation, arrangements, agencies and interactions in patients' rooms, and suggested how they might be managed to benefit health and care (Selanders, 1998; Andrews, 2003, 2016). Nightingale's Notes lays contextual issues as a cornerstone in the earliest foundations of modern nursing. Like most nurses after her she understood that nursing incorporates a fundamental responsibility for the places where patients reside (Andrews, 2016). 
Fast forward eighty years and the idea of 'nursing environment' re-surfaced within burgeoning mid twentieth century scholarship as a core concept of nursing theory (theories of nursing) (Thorne et al., 1998; Andrews and Moon, 2005b; Andrews, 2016). In particular, nurse theorists pondered and debated what constituted nursing environment. In terms of general thinking, as Fitzpatrick and Whall (1983) argue, there was a distinction drawn between facets of nurses' bodies (considered to be 'internal' events) and everything else conceivable (considered to be 'external' events). One line of thinking separated internal and external events; internal being nurses themselves, and external - such as other humans (Peplau, 1952) and physical contexts (Orlando, 1961) - being the environment. A second line of thinking, however, brought internal and external events closer together - (for example linking personal physiology and psychology together with health system and social facets, Levine, 1969; Patterson and Zderad, 1976; Neuman, 1980) - thus demonstrating interaction between the two levels of environment. A third line meanwhile erased the boundaries between internal and external events and instead emphasised their interplay and co-dependence. Here, environment could be imagined more fluidly, for example, as movement exchanges of energy, matter and knowledge (Roy, 1976; Rogers, 1980; Parse, 1981). All three of these approaches to 'nursing environment' were part of a zeitgeist for grand theories that would help justify, secure and build nursing as a legitimate profession and discipline, distinct and somewhat independent from medicine (Andrews, 2016).

\subsection{The second wave: environment as a broad empirical concern}

In recent decades, while emphasis on 'big' nursing theory has declined, interest in researching nursing environments has not. Rather, a broad practical empirical engagement with environments has emerged and foregrounded a range of focused areas of interest (Andrews, 2016). One prominent example would be 'work environments'. Studies grapple with issues such as the support, empowerment and opportunity they provide/do not provide (Haugh and Laschinger, 1996; Almost and Spence-Laschinger, 2002; Tourangeau et al., 2009), or their social functioning and what makes them psychologically healthy or unhealthy (Leveck and Jones, 1996; Dendaas, 2004, 2010; Lavoie-Tremblay et al., 2008; Vessey et al., 2009), or how their architecture and design features can impact care and outcomes (Williams, 2001; Parker et al., 2004; Becker, 2007; Marquardt and Schmieg, 2009). Similarly, nursing environment has also emerged in discussions of leadership capacity, such as settings for practice enhancement and development strategies (McCormack and McCance, 2011; McCormack et al., 2013), as 'contexts' - with political, economic and social variability - that help or hinder research knowledge translation (Kitson et al., 1998; Rycroft-Malone, 2004; Rycroft-Malone et al., 2013) and in specific forms as high performing and attractive "magnet' institutions (Scott et al., 1999; Buchan, 1999; Upenieks, 2003). Continuing this latter theme, nursing environment has also been mobilised in debates on the 'best places' to care, as in the case of institutionalized settings versus homes (West et al., 2000; Watty et al., 2003; Parratt and Fahy, 2004), and through debates on the nature and importance of physical proximity and presence in caring interactions and relationships (Osterman and Schwartz-Barcott, 1996; Melnechenko, 2003; MacKinnon et al., 2005), particularly given the emergence of nursing in cyberspace in the last two decades (Hern et al., 1997; Cudney and Weinert, 2000). Meanwhile, the entrenchment of clinical practice in local communities, and the nature and importance of communities, are recurrent themes (Hall, 1996;
Pardo Mora and González Ballesteros, 2007), including in the contexts of urban living (Vandemark, 2007; Skott and Lundgren, 2009; DeGuzman and Kulbok, 2012; Thomas, 2013a), and rural living (Bigbee, 1993; Shreffler, 1996; Leipert and Reutter, 1998; Leipert and Anderson, 2012). Furthermore, 'natural environment' has become a well-trodden area of interest in nursing research, paralleling the emergence of the green movement (see Kleffel, 1991; Schuster and Brown, 1994; Chinn, 1996). Whilst much of this work is locally-focused and concerned with pollution and 'environmental health' (Grady et al., 1997; Larsson and Butterfield, 2002; Sweeney and de Peyster, 2005), some considers the impacts on health of broader global climate and ecosystems change (Kleffel, 1996; Kirk, 2002; Laustsen, 2006; Andrews, 2009).

\subsection{The third wave: geographies in nursing}

In the mid-1990s a series of key papers on the ethics of place by Liaschenko (1994; 1996a, 1996b; 1997) drew more directly on human geography and subsequently many review papers have encouraged and gradually articulated geographical perspectives in the nursing literature (see Andrews, 2002; Andrews, 2016; Andrews and Moon, 2005a, 2005b; Carolan et al., 2006; Solberg and Way, 2007; Atherton and Kyle, 2014; Kyle and Atherton, 2016).

Transformations in contemporary healthcare - and specifically nursing - are by nature geographical in their making, form and consequences and thus beg a specifically geographical research perspective. Andrews (2016) describes five developments as particularly important: i) the continued ascendancy and acceptance of the social model of health as foundation for nursing knowledge, which is, implicitly also a spatial model; ii) the increasing spatial diffusion of the nursing role; iii) changes in hospitals as commercial places; iv) the increasing use of place as a concept to frame health policy and administration; v) and the continued process of globalization whereby nursing policy, employers, representative organisations, regulators, information, evidence, workforce and responsibilities now reach across vast geographical distances and bridge multiple territorial jurisdictions. As Andrews (2016) also notes, in the academic arena concurrent shifts in debate have provided fertile ground for geography's flourishing in nursing scholarship. The turn to geography can variously be considered as a manifestation of the natural, maturing and expansion of nursing research that over the past decade has developed a range of dedicated social science branches; part of broader 'spatial turns' that have taken place across a range of academic, health, humanities and social science disciplines over the past two decades; and as an opportunity created by the relative neglect of nursing as an empirical subject by medical/health geographers (as they attempted, in the $1990 \mathrm{~s}$, to distance their sub-discipline from its earlier tradition of doing mainstream health services research).

Three broad epistemological approaches have shaped the foci of scholars' activity in these third wave geographies of nursing. A positivistic 'spatial science' approach has concerned itself with aerial differentiation and the quantitative calculation of distributive trends across space (traditional 'mapping', typically of people, diseases, services and other resources) often using Geographical Information Systems (for example Lin et al., 1997; Moss and Schell, 2004; Courtney, 2005; Endacott et al., 2009; Graves, 2012). Usually working at the meso- and macro-scales, scholars have used statistical models, probability testing and other approaches to find spatial patterns in health and health care phenomenon important to nurses. Empirically, attention has focused, for example, on area-based social determinants of health (Bushy, 1990; Edgecombe, 1999), and on the distributive fea- 
tures of nursing workforces and the social, political and economic forces that shape them at local (Brodie et al., 2005), national (Kovner et al., 2011; Harris et al., 2013; Cho et al., 2014) and international scales (Buchan, 2001; Kingma, 2006; Kline, 2003; Aiken et al., 2004; Brush and Sochalski, 2007; Bach, 2015). A third focus has been the distributive qualities and concerns of particular client and population groups that nurses have responsibility for (see Moss and Schell, 2004; Hodgins and Wuest, 2007; Thomas, 2013b).

Arising simultaneously, a Marxist based political economy tradition posits that spatial arrangements of resources and services are the realisation of broader social and economic processes and relations. Empirically, the focus here is to research how health systems and policies play out geographically or have geographical implications (both spatial science and political economy often being motivated by ideas around 'distributive justice' and optimal allocations across space) (Andrews, 2016). Indeed, in explaining distributive features in the supply of nursing and their relationships to health needs, patterns and outcomes, this is a perspective that speaks directly to debates on efficiency and equity in health service planning (for example Andrews and Phillips, 2002; Kingma, 2003; Aiken et al., 2004; Brush and Sochalski, 2007).

A third and very popular geographical tradition draws theoretically on social constructivism and humanism, and is more qualitative methodologically. Empirically it is concerned with experience; how places represent and make people, and how people represent and make places. Studies engage with how the career category 'nurse', its collective manifestation 'nursing', and the many activities that constitute the action 'to nurse', relate to place (Andrews, 2016). A range of relationships have been described including how places are attributed symbolic identity by, and in relation to, nurses (Savage, 1997; Halford and Leonard, 2003; Cheek, 2004; Gilmour, 2006), and thus how places characterise and express particular professional nursing specialisms. Place has been positioned as crucial to the nature of mental health care (Montgomery, 2001; Andes and Shattell, 2006), community health (Bender et al., 2007), home care (Duke and Street, 2003), gerontology and geriatrics (Cheek, 2004) and midwifery (Lock and Gibb, 2003). Other studies have investigated the dynamics between places and nurse-patient decisions, ethics, interactions and relationships (Purkis, 1996; Malone, 2003; Bucknall, 2003; Peter and Liaschenko, 2004; Shattell et al., 2008; Seto-Nielsen et al., 2013). Finally, the dynamics between places and intra- and inter-professional interactions and relationships (West and Barron, 2005; Barnes and Rudge, 2005; Oandasan et al., 2009; Kitto et al., 2013), and those between places and the nature and outcomes of care (including through place-based clinical interventions) (McKeever et al., 2002; Angus et al., 2003; Hodnett et al., 2005, 2009; Marshall, 2008; Mesman, 2012) have been a focus of constructivist/humanist scholars.

The aforementioned scholarship notwithstanding, the full potential of geography for nurse education has hitherto remained unrealised. Although the social sciences in general, have been a component of nursing curricula for some time, the theoretical rationale for their inclusion has been poorly developed (Edgley et al., 2009) and students often struggle to see the relevance of the social sciences for the practice of nursing (Aranda and Law, 2007). Therefore, we call for a new wave of scholarly engagement between geography and nursing that focuses explicitly on nurse education and which seeks to generate a platform for a more coherent, social science-informed critical pedagogy.

\subsection{The fourth wave: geography as a critical pedagogy}

We imagine that a fourth wave of scholarship would co-exist with, and complement, earlier waves, not least because they also share a concern for education: to enable professionals to challenge medical models of health with a social (and implicitly spatial) alternative in the first; to stress the vitality of place to health and healing to students in the second. In the third wave geography found its way into the classroom through research that encouraged students to consider the spatial dimensions of care delivery, experiences and outcomes at a range of scales. What would make a fourth wave different is that it would focus explicitly on translating insights from research into 'impact' on the curriculum of nurse training. The resultant more coherent critical pedagogy would ensure valuable social science perspectives 'impact' (inform) better nursing practice beyond training in our public health service. This would involve embedding geographical ideas in nursing degrees ranging from full curriculum to the teaching of individual modules and lectures. Such an approach would instil social science from the ground up, embed it in the training every nurse received and thus would be more likely to create generational changes in thinking geographically 'at the bedside, in homes, on the street'. To date little attention has been given to such a project (Andrews, 2006). This paper showcases the approach in action by taking a case study research paper and translating its insights in ways that might encourage critical geographical thinking among student nurses and reflexive clinical practice among nursing graduates.

\section{Transfusing blood, infusing insights}

Blood donor selection is one example of how everyday nursing practice is enmeshed in complex assemblages of interpersonal care, research-based risk assessment procedures, screening technology, and nationally and internationally debated health policy. It is also another illustration of nurses' position in the front line of huge public sector organisations that rely on maintaining a relationship of trust and confidence between caregivers and patients. In their recent paper, Kesby and Sothern (2014) discuss the thorny issue of who may donate blood. Here we tease out three ways in which research like this can inform a critical pedagogy for nurse education. Specifically, we illustrate how a critical understanding of the ways in which health data are generated, collated and mobilised can help student nurses better understand how clinical practice is shaped, their central role within it and their potential, once qualified, to feedback on and improve the workings of public health delivery.

Nurses are closely involved in administering donor-health check questionnaires (especially where a donor is deferred). This questioning is necessary because, while all blood is screened, tests remain imperfect since for some blood borne infections (BBI, e.g. Hepatitis or HIV) false negatives can be returned in the 'window period' between transmission and the test's ability to detect infection. Thus, the questionnaire seeks to identify individuals more likely to have contracted a BBI recently. In the UK the primary mode of transmission for HIV and Hepatitis is sexual contact; therefore part of the pre-donation questionnaire is used to profile, and exclude from the donor pool, individuals whose "practices and lifestyle" are deemed to present a higher risk of recent BBI infection and therefore a window period donation.

Controversy has raged around the group exclusion of men-who-have-sex-with-men (MSM). Human Rights groups have complained this is a violation of rights and unjustly denies MSM opportunity to demonstrate inclusion and citizenship. In response, medics 
demiological researchers argue that the science demonstrates higher prevalence of HIV and Hepatitis among MSM as a population. While a policy revision in 2011 ended their total exclusion, enabling donation after 12-months abstinence, sexually active MSM remain indefinitely excluded. Kesby and Sothern (2014) invite readers to look closely at the science (its assumptions, methods and epistemology), and to question what this means for risk assessment.

Whilst nurses involved with donation question and defer at the individual scale, they are operationalising a risk assessment procedure based on large scale aggregate data. Questioning potential donors about "practices and lifestyle", actually ascribes individuals to broad and relatively undifferentiated population categories (associated with higher or lower risk), and identifies any recent sexual contact with a person from a category deemed high-risk for BBI (e.g. commercial sex workers, some recent migrants, active MSM).

Nurses working in genitourinary medicine (GUM) treat many MSM for STIs, but know that incidence is strongly associated with particular behaviours (e.g. frequent multiple partnering especially when associated with unprotected receptive anal sex). They also know that the same high-risk activity and associated STI infection are increasingly common among many heterosexuals, as are complex sexual networks. Reflection from this perspective on the rhetoric of "practices and lifestyles" framing UK blood donor selection, reveals that apart from asking about recent partners, the questionnaire asks no ontologically relevant questions about actual high/low risk sexual practice. MSM's sense of injustice at being excluded on the basis of a population-scale lifestyle category (active MSM) rather than specific practice (many MSM are monogamous and/or use protection consistently and/or do not engage in anal sex) becomes easier to appreciate.

This homogenisation of MSM is a classic example of what Robinson (1950) called the 'ecological fallacy': assuming individual risk based on population level profiling. Importantly however, this is equally true of the much bigger 'general [heterosexual] population'. This largely un-disaggregated category (against which the relative risk of the small MSM-group is compared) conceals within it a minority (but numerically large number) of heterosexuals who also engage in clinically relevant higher-risk sexual practice and who carry BBIs. Presently these individuals are able to donate because they are asked nothing about practices, only whether they, or their immediate partners have a direct connection to high-risk regions or groups (Kesby and Sothern, 2014).

Current deferment policy is based on epidemiological science but social science offers alternative approaches to donor selection, grounded in ontologically relevant profiling of individual donors' sexual history. Those favouring epidemiology fear that practice-based questioning would deter donation, would be complex, and doubt that donors can be trusted to report their own sexual risk-taking (NHSBT, 2011). GUM Nurses have much experience of individual assessments and nurses working in blood donation are well placed to know that a small number of carefully directed questions could identify and exclude the bulk of individuals pursuing the highest risk practices (across all groups), thereby minimising stress on imperfect screening processes. Furthermore, social science training would make them familiar with effective ways to deliver practice-based questions that reduce embarrassment among the highly motivation donor cohort (e.g. "yes or no - do any of the following apply to you...? If yes, then please defer 12 months"). Finally, nurses know that trust between patients and clinicians is vital to the care relationship and appreciate it is co-constituted with patients.

\section{Reframing research impact}

The case study above illustrates in three broad ways how research in health geography might infuse nurse education with insights that facilitate the emergence of a critical pedagogy.

Nurse education should challenge student nurses to practice reflexively. Our case study highlights how knowledge of others is shaped by data that nurses and other health professionals collect routinely and the categories used to structure these data. Arguably, epistemological and ontological concerns remain abstract in many nursing curricula. To be meaningful, and to demonstrate why there is a need to think about the degree to which methods of data collection and analysis accurately represent the clinical phenomena being managed, accessible and clinically grounded examples are needed. Modern nursing requires and encourages graduates to be much more cognisant of the science, statistics, technology and research behind the care they give, and an education that encourages reflexive practice will also enable increasingly highly qualified nurses to offer useful critique of existing practice that improves service delivery.

Second, nurse education should encourage students to think geographically. A fourth wave critical pedagogy would augment earlier waves of geographical insight on the ways in which context shapes individuals' lives, circumstances and experiences, by encouraging students to appreciate that questions of the scaling of data and categories are not innocent and can have profound impacts on their own thinking and on the treatment experience of patients. In their practice, graduate nurses should regularly ask themselves whether the scales and categories they are utilising have a good fit with the clinical phenomena they are treating.

Third, a critical pedagogy would encourage student nurses to act justly. Our exemplar foregrounds one example in which, despite their best intensions, nurses might find themselves acting - or being perceived to act - unjustly. Because nurses are very much in the frontline of the health service, they play a critical role in maintaining the social contract of trust and confidence that is so vital to effective health care delivery. They need to be able to speak assuredly to questions of policy and procedures to ensure patient confidence. In modern nursing, they have a key role to play in feeding back to senior clinicians and researchers when that confidence is challenged. Qualified nurses that are confident in their social science, as well as their clinical training, will be more confident to make these critical self-regulating observations to senior managers.

These are some of the ways in which research in health geography can have impact on public service delivery through enhancing the $e d u$ cation of future healthcare professionals. Health geography's strength (like nursing) lies in its ability to straddle the applied and theoretical, and its intuitive care and concern for people and place. It is well placed therefore to encourage other social science disciplines, such as demography, medical sociology (Allen, 2001), and anthropology to make similar contributions to a new critical pedagogy. (Health) geography's embrace of critical feminist scholarship (Liaschenko, 1997; Peter, 2002; Halford and Leonard, 2003; Dyck, 2003) that wrestles with the gendered meaning and control of (work) places provides a further point of alignment with nursing as part of platform for critical nursing pedagogy.

Enhancing 'mindliness' (Greenhaugh and Fahy, 2015) through education is, we suggest, impact worth striving for within the academy. Academics need to recognise that existing audit procedures like REF do already allow 'impact' "within the higher education sector, including on teaching or students", as long as they "extend significantly beyond the submitting HEI [Higher Education Institution]" (HEFCE, 
2012) (although it is often safer to claim such educational impact as part of a broader case study). This said, there is room for both government and HEIs to rethink the degree to which the impact of research on students and processes of education, is explicitly acknowledged and encouraged, particularly in fields and disciplines like nursing where graduates have a very real and immediate influence on 'society, public policy or services, health and quality of life' etc. Reframing research impact in this way would recognise and encourage the kind of integrated scholarship that may academics have continued to pursue despite the pressures from neo-liberal performance management that have consistently underemphasised teaching. Not only might this enable a resurgence of the academy as a critical social institution, committed to innovative pedagogy and truly collaborative cross-disciplinary endeavour, it might simultaneously service government's desire that publicly-funded research should have 'impact', and speak to the growing realisation among HEIs that high-quality teaching is not only their core business but also the key source of their base income.

To support this endeavour, we call in closing, for health geographers and nurse educators to unite under this common agenda and work together to advance the fourth wave of enquiry at the intersection between geography and nursing education in three critical ways: First, we encourage health geographers to translate their research for nursing students to enable their research to cross disciplinary boundaries. Second, we encourage health geographers to teach students following nursing programmes. Save a few exceptions, geographers are rare in nursing Schools, and fewer still engage in delivery of undergraduate education. More needs to be done to bring their geographical insights into the classroom and clinical settings. Third, we call on both health geographers and nurse educators to transfuse our lifeblood by enabling their respective students to learn together in classrooms, clinical settings or, indeed, on joint field classes. Providing opportunities for students from both nursing and geography to discuss their respective ways of seeing the world might trigger new mutually beneficial understandings and, perhaps in time, unknown impacts beyond the academy.

\section{Conclusion}

The recent addition to academic audits of measures of 'impact' has tended to further marginalise the critical social function that higher education plays in educating the population. While definitions of impact in the 2014 UK REF assessment did allow for teaching to be an activity in which impact could be demonstrated, few institutions seemed to recognise this and focused instead on collecting data on the impacts of research beyond the academy on policy and commercial activity. This side-lining of the impacts of research on education and training within the academy extended the trend already produced by several decades of research audit. In the new era of declining research budgets, new emphasis on Teaching Excellence Frameworks and institutional recognition of income through teaching, it seems appropriate to encourage academics and institutions to recognise the opportunity to demonstrate research impact on teaching and to call for reforms to the definition of impact to better recognise and encourage such activity.

Using a case study that critiqued existing blood donor risk evaluation, the paper called for a fourth wave of the long-standing interaction between health geography and nurse education. This should focus explicitly on a new critical pedagogy inspired by social-scientific research that encourages nurses to practice reflexively, think geographically, and act justly once qualified.
Health geographers who desire their research to have impact, should seek to achieve this by translating research findings into useful materials for nursing curricula, teaching nursing students, and creating opportunities to enable student nurses and geographers to learn together, thereby positively affecting the professional practice of future healthcare professionals.

We challenge the inevitability of the retrenchment of disciplinary boundaries in response to performance management regimes, and contest narrow visions of research impact that elide the primary purpose of universities to provide transformational education. Instead, we point out it is in all parties' interest to explore trans-disciplinary knowledge production and exchange and ensure that students, the life blood of our disciplines and of society, are enthused by a transfusion of ideas between research and teaching and between one discipline and another, in ways that impact positively public health and health care delivery in the future.

\section{Acknowledgements}

The idea for this paper was sparked during conversations between us at the opening seminar of the Social Science and Nurse Education seminar series at the Highland Campus in Inverness in May 2014. We wish to thank the Economic and Social Research Council (ESRC) for funding this seminar series (Grant Number: ES/L000741/1); participants at the 16th International Medical Geography Symposium (IMGS) in Vancouver in July 2015, at which these ideas received their first public airing, for their supportive and constructive comments and questions; and the Editor and three anonymous peer reviewers for their generous and insightful remarks on an earlier draft of this manuscript.

\section{References}

Aiken, L.H., Buchan, J., Sochalski, J., Nichols, B., Powell, M., 2004. Trends in international nurse migration. Health Aff. 23 (3), 69-77.

Allen, D., 2001. Nursing and sociology: an uneasy marriage?. Sociol. Health \& Illn. 23 (3), 386-396.

Almost, J., Spence Laschinger, H.K., 2002. Workplace empowerment, collaborative work relationships, and job strain in nurse practitioners. J. Am. Acad. Nurse Pract. 14 (9), 408-420.

Andes, M., Shattell, M.M., 2006. An exploration of the meanings of space and place in acute psychiatric care. Issues Ment. Health Nurs. 27 (6), 699-707.

Andrews, G.J., 2002. Towards a more place-sensitive nursing research: an invitation to medical and health geography. Nurs. Inq. 9 (4), 221-238.

Andrews, G.J., 2003. Nightingale's geography. Nurs. Inq. 10 (4), 270-274

Andrews, G.J., 2006. Geographies of health in nursing. Health \& Place 12 (1), $110-118$.

Andrews, G.J., 2009. Global climate change: a framework for nursing action. Aporia $1(1), 22-29$

Andrews, G.J., 2016. Geographical thinking in nursing inquiry, part one: locations, contents, meanings. Nurs. Philos. (doi:10.1111/nup.12133).

Andrews, G.J., Moon, G., 2005a. Space, place, and the evidence base: Part I-an introduction to health geography. Worldviews Evidence-Based Nurs. 2 (2), 55-62.

Andrews, G.J., Moon, G., 2005b. Space, place, and the evidence base: Part II-rereading nursing environment through geographical research. Worldviews Evidence-Based Nurs. 2 (3), 142-156.

Andrews, G.J., Phillips, D.R., 2002. Changing local geographies of private residential care for older people 1983-1999: lessons for social policy in England and Wales. Soc. Sci. Med. 55 (1), 63-78.

Angus, J., Hodnett, E., O'Brien-Pallas, L., 2003. Implementing evidence-based nursing practice: a tale of two intrapartum nursing units. Nurs. Inq. 10 (4), 218-228.

Aranda, K., Law, K., 2007. Tales of sociology and the nursing curriculum: revisiting the debates. Nurse Educ. Today 27 (6), 561-567.

Atherton, I.M., Kyle, R.G., 2014. Habitat and health: why place matters. Nurs. Stand. 29 (3), 24-25.

Bach, S., 2015. Nurses across borders: the international migration of health professionals. In: Parry, B., Greenhough, B., Brown, T., Dyck, I. (Eds.), Bodies across Borders: the Global Circulation of Body Parts, Medical Tourists and Professionals. Ashgate. 
Barnes, L., Rudge, T., 2005. Virtual reality or real virtuality: the space of flows and nursing practice. Nurs. Inq. 12 (4), 306-315.

Becker, F., 2007. Nursing unit design and communication patterns: what is "real" work?. Health Environ. Res. Des. J. 1 (1), 58-62.

Bender, A., Clune, L., Guruge, S., 2007. Considering place in community health nursing. Can. J. Nurs. Res. 39 (3), 20-35.

Bigbee, J.L., 1993. The uniqueness of rural nursing. Nurs. Clin. N. Am. 28 (1), $131-144$.

Brodie, D.A., Andrews, G.J., Andrews, J.P., Thomas, B.G., Wong, J., Rixon, L., 2005 Working in London hospitals: perceptions of place in nursing students' employment considerations. Soc. Sci. Med. 61 (9), 1867-1881.

Brush, B.L., Sochalski, J., 2007. International nurse migration lessons from the Philippines. Policy, Polit. Nurs. Pract. 8 (1), 37-46.

Buchan, J., 1999. Still attractive after all these years? Magnet hospitals in a changing health care environment. J. Adv. Nurs. 30 (1), 100-108.

Buchan, J., 2001. Nurse migration and international recruitment. Nurs. Inq. 8 (4), 203-204.

Bucknall, T., 2003. The clinical landscape of critical care: nurses' decision-making. J. Adv. Nurs. 43 (3), 310-319.

Bushy, A., 1990. Rural determinants in family health: considerations for community nurses. Fam. Community Health 12 (4), 29-38.

Carolan, M., Andrews, G.J., Hodnett, E., 2006. Writing place: a comparison of nursing research and health geography. Nurs. Inq. 13 (3), 203-219.

Cheek, J., 2004. Older people and acute care: a matter of place. Illn. Crisis Loss 12 (1), 52-62.

Chinn, P.L., 1996. Environment, health and nursing. Adv. Nurs. Sci. 18 (4). viii.

Cho, S.H., Lee, J.Y., Mark, B.A., Jones, C.B., 2014. Geographic mobility of Korean new graduate nurses from their first to subsequent jobs and metropolitan-nonmetropolitan differences in their job satisfaction. Nurs. Outlook 62 (1), 22-28.

Courtney, K.L., 2005. Visualizing nursing workforce distribution: policy evaluation using geographic information systems. Int. J. Med. Inf. 74 (11), 980-988.

Cudney, S., Weinert, C., 2000. Computer-based support groups: nursing in cyberspace. Comput. Nurs. 18, 35-46.

DeGuzman, P.B., Kulbok, P.A., 2012. Changing health outcomes of vulnerable populations through nursing's influence on neighborhood built environment: a framework for nursing research. J. Nurs. Scholarsh. 44 (4), 341-348.

Dendaas, N., 2004. The scholarship related to nursing work environments: where do we go from here?. Adv. Nurs. Sci. 27 (1), 12-20.

Dendaas, N., 2010. Environmental congruence and work-related stress in acute care hospital medical/surgical units: a descriptive, correlational study. HERD 5 (1) $23-42$.

Duke, M., Street, A.E., 2003. Hospital in the home: constructions of the nursing role: a literature review. J. Clin. Nurs. 12, 852-859.

Dyck, I., 2003. Feminism and Health Geography: twin tracks or divergent agendas?. Gend. Place \& Cult. A J. Feminist Geogr. 10 (4), 361-368.

Edgecombe, G., 1999. Guest editorial: social determinants of health, the physical environmen and Public Health Nursing. Contemp. Nurse 8 (1), 219-220.

Edgley, A., Timmons, S., Crosbie, B., 2009. Desperately seeking sociology: nursing student perceptions of sociology on nursing courses. Nurse Educ. Today 29 (1), $16-23$.

Endacott, R., Boulos, M.N.K., Manning, B.R., Maramba, I., 2009. Geographic Information Systems for healthcare organizations: a primer for nursing professions. Comput. Inf. Nurs. 27 (1), 50-56.

Fitzpatrick, J., Whall, A., 1983. Conceptual Models of Nursing: Analysis and Application. Prentice-Hall, London.

Gilmour, J.A., 2006. Hybrid space: constituting the hospital as a home space for patients. Nurs. Inq. 13 (1), 16-22.

Grady, P., Harden, J.T., Mortiz, P., Amende, L.M., 1997. Incorporating environmenta sciences and nursing research: an NINR initiative. Nurs. Outlook 45 (2), 73-75.

Graves, B.A., 2012. Geographical information systems and the analysis of health for rural populations. Online J. Rural Nurs. Health Care 8 (1), 11-12.

Greenhaugh, T., Fahy, N., 2015. Research impact in the community-based health sciences: an analysis of 162 case studies from the 2014 Research Excellence Framework. BMC Med. 13, 232

Halford, S., Leonard, P., 2003. Space and place in the construction and performance of gendered nursing identities. J. Adv. Nurs. 42 (2), 201-208.

Hall, J.M., 1996. Geography of childhood sexual abuse: women's narratives of their childhood environments. Adv. Nurs. Sci. 18 (4), $29-47$.

Harris, A., McGillis Hall, L., Peterson, J., Price, S., Lalonde, M., Andrews, G.J., McDonald Rencz, S., 2013. LPN perspectives on factors that affect nurse mobility in Canada. Can. J. Nurs. Leadersh. 26, 70-78.

Haugh, F.B., Laschinger, H.S., 1996. Power and opportunity in public health nursing work environments. Public Health Nurs. 13 (1), 42-49.

Hern, M., Weitkamp, T., Haag, D., Trigg, J., Guard, J., 1997. Nursing the community in cyberspace. Comput. Nurs. 15, 316-323.

Higher Education Funding Council for England, 2012. Assessment Framework and Guidance on Submissions. REF 02.2011. HEFCE, Bristol.

Higher Education Funding Council for England (HEFCE), 2011. Decisions on Assessing Research Impact. REF 01.2011 HEFCE, Bristol.
Hodgins, H.J., Wuest, J., 2007. Uncovering factors affecting use of the emergency department for less urgent health problems in urban and rural areas. Can. J. Nurs. Res. 39 (3), 78-102.

Hodnett, E.D., Downe, S., Edwards, N., Walsh, D., 2005. Home-like versus conventional institutional settings for birth. Birth 32 (2). 151-151.

Hodnett, E.D., Stremler, R., Weston, J.A., McKeever, P., 2009. Re-conceptualizing the hospital labor room: the place (pregnant and laboring in an ambient clinical environment) pilot trial. Birth 36 (2), 159-166.

Kesby, M., Sothern, M., 2014. Blood, sex and trust: the limits of the population-based risk management paradigm. Health \& Place 26, 21-30.

Kingma, M., 2003. Economic incentive in community nursing: attraction, rejection or indifference. Hum. Resour. Health 1 (2), 1-12.

Kingma, M., 2006. Nurses on the Move: Migration and the Global Health Care Economy. Cornell University Press.

King's College London, 2015. The Nature, Scale and Beneficiaries of Research Impact: an Initial Analysis of Research Excellence Framework (REF) 2014 Impact Case Studies. King's College London, London.

Kirk, M., 2002. The impact of globalization and environmental change on health: challenges for nurse education. Nurse Educ. Today 22 (1), 60-71.

Kitson, A., Harvey, G., McCormack, B., 1998. Enabling the implementation of evidence based practice: a conceptual framework. Qual. Health Care 7 (3), 149-158.

Kitto, S., Nordquist, J., Peller, J., Grant, R., Reeves, S., 2013. The disconnections between space, place and learning in interprofessional education: an overview of key issues. J. Interprofessional Care 27 (S2), 5-8.

Kleffel, D., 1991. An ecofeminist analysis of nursing knowledge. Nurs. Forum 26 (4), $5-18$.

Kleffel, D., 1996. Environmental paradigms: moving toward an ecocentric perspective. Adv. Nurs. Sci. 18 (4), 1-10.

Kline, D.S., 2003. Push and pull factors in international nurse migration. J. Nurs. Scholarsh. 35 (2), 107-111.

Kovner, C.T., Corcoran, S.P., Brewer, C.S., 2011. The relative geographic immobility of new registered nurses calls for new strategies to augment that workforce. Health Aff. 30 (12), 2293-2300.

Kyle, R.G., Atherton, I.M., 2016. Biogeography as critical nursing pedagogy: breathing life into nurse education. Nurse Educ. Pract. (doi:10.1016/j.nepr.2016.07.006).

Kyle, R.G., Milligan, C., Kearns, R.A., Larner, W., Fyfe, N.R., Bondi, L., 2011. The tertiary turn: locating 'the academy' in autobiographical accounts of activism in manchester, UK and auckland, aotearoa New Zealand. Antipode 43 (4), 1181-1214.

Larsson, L.S., Butterfield, P., 2002. Mapping the future of environmental health and nursing: strategies for integrating national competencies into nursing practice. Public Health Nurs. 19 (4), 301-308.

Laustsen, G., 2006. Environment, ecosystems, and ecological behavior: a dialogue toward developing nursing ecological theory. Adv. Nurs. Sci. 29 (1), 43-54

Lavoie-Tremblay, M., Wright, D., Desforges, N., Gélinas, C., Marchionni, C., Drevniok, U., 2008. Creating a healthy workplace for new-generation nurses. J. Nurs. Scholarsh. 40 (3), 290-297.

Leipert, B., Anderson, E., 2012. Rural nursing education: a photovoice perspective. Rural Remote Health 12 (2061)

Leipert, B., Reutter, L., 1998. Women's health and community health nursing practice in geographically isolated settings: a Canadian perspective. Health Care Women Int. 19 (6), 575-588.

Leveck, M.L., Jones, C.B., 1996. The nursing practice environment, staff retention, and quality of care. Res. Nurs. Health 19 (4), 331-343.

Levine, M.E., 1969. Introduction to Clinical Nursing. F.A. Davis, Philadelphia

Liaschenko, J., 1994. The moral geography of home care. Adv. Nurs. Sci. 17, 16-25.

Liaschenko, J., 1996a. A sense of place for patients: living and dying. Home Care Provid. 1, 270-272.

Liaschenko, J., 1996b. Home is different: on place and ethics. Home Care Provid. 1 (1), 49-50.

Liaschenko, J., 1997. Ethics and the geography of the nurse- patient relationship: spatial vulnerabilities and gendered space. Sch. Inq. Nurs. Pract. 11, 45-59.

Lin, G., Burns, P.A., Nochajski, T.H., 1997. The geographic distribution of nurse practitioners in the United States. Appl. Geogr. Stud. 1 (4), 287-301.

Lock, L.R., Gibb, H.J., 2003. The power of place. Midwifery 19, 132-139.

MacKinnon, K., McIntyre, M., Quance, M., 2005. The meaning of nurse's presence during childbirth. J. Obstetric, Gynecol. Neonatal Nurs. 34, 28-36.

Malone, R., 2003. Distal nursing. Soc. Sci. Med. 56, 2317-2326.

Marquardt, G., Schmieg, P., 2009. Dementia-friendly architecture: environments that facilitate wayfinding in nursing homes. Am. J. Alzheimer's Dis. other dementias 24 (4), 333-340.

Marshall, E.S., 2008. Home as place for healing. Adv. Nurs. Sci. 31 (3), 259-267.

Martin, B.R., 2011. The Research Excellence Framework and the 'impact' agenda: are we creating a Frankenstein Monster?. Res. Eval. 20 (3), 247-254.

McCormack, B., McCance, T., 2011. Person-centred Nursing: Theory and Practice. John Wiley \& Sons.

McCormack, B., Manley, K., Titchen, A., 2013. Practice Development in Nursing and Healthcare. John Wiley \& Sons. 
McKeever, P., Stevens, B., Miller, K.L., MacDonell, J.W., Gibbins, S., Guerriere, D., Dunn, M.S., Coyte, P.C., 2002. Home verses hospital breastfeeding support for newborns: a randomized controlled clinical trial. Birth 29 (4), 258-265.

Melnechenko, K., 2003. To make a difference: nursing presence. Nurs. Forum $38,18-25$.

Mesman, J., 2012. Moving in with care about patient safety as a spatial achievement. Space Cult. 15 (1), 31-43.

Montgomery, P., 2001. Shifting meaning of asylum. J. Adv. Nurs. 33 (4), 425-431.

Moss, M., Schell, M., 2004. GIS(c): a scientific framework and methodological tool for nursing research. Adv. Nurs. Sci. 27 (2), 150-159.

Neuman, B., 1980. The Betty Neuman health-care systems model: a total person approach to patient problems. In: Riehl, J.P., Roy, C. (Eds.), Conceptual Models for Nursing Practice, second ed. Appleton-CenturyCrofts, New York.

Nightingale, F., 1859. Notes on Nursing: what it Is and what it Is Not. Lippincott, London.

NHSBT (NHS Blood and Transplant), 2011. Why Men Who Have Sex with Men Are Deferred from Blood Donation for 12 Months Position Statement: November 2011. NHS Blood and Transplant, London.

Oandasan, I.F., Gotlib Conn, L., Lingard, L., Karim, A., Jakubovicz, D., Whitehead, C., Reeves, S., 2009. The impact of space and time on interprofessional teamwork in Canadian primary health care settings: implications for health care reform. Prim. Health Care Res. Dev. 10 (2), 151-162.

Orlando, I.J., 1961. The Dynamic Nurse-patient Relationship. G.P. Putman's Sons, New York.

Osterman, P., Schwartz-Barcott, D., 1996. Presence: four ways of being there. Nurs. Forum 31, 23-30.

Pain, R., Kesby, M., Askins, K., 2011. Geographies of impact: power, participation and potential. Area 43 (2), 183-188.

Pardo Mora, Y.Y., González Ballesteros, M.M., 2007. Space and territory in community nursing practice. Aquichán 7 (2), 189-198.

Parker, C., Barnes, S., McKee, K., Morgan, K., Torrington, J., Tregenza, P., 2004. Quality of life and building design in residential and nursing homes for older people. Ageing Soc. 24 (06), 941-962.

Parratt, J., Fahy, K., 2004. Creating a 'safe' place for birth: an empirically grounded theory. N. Z. Coll. Midwives J. 30, 11-14.

Parse, R.R., 1981. Man-living-health: a Theory of Nursing. Wiley, New York.

Patterson, J.C., Zderad, L.T., 1976. Humanistic Nursing. Wiley, New York.

Penfield, T., Baker, M.J., Scoble, R., Wykes, M.C., 2014. Assessment, evaluations, and definitions of research impact: a review. Res. Eval. 23, 21-32.

Peplau, H.E., 1952. Interpersonal Relationships in Nursing. G.P. Putman's Sons, New York.

Peter, E., 2002. The history of nursing in the home: revealing the significance of place in the expression of moral agency. Nurs. Inq. 9 (2), 65-72.

Peter, E., Liaschenko, J., 2004. Paradoxes of proximity: a spatio-temporal analysis of moral distress and moral ambiguity. Nurs. Inq. 11 (4), 218-225.

Purkis, M.E., 1996. Nursing in quality space: technologies governing experiences of care. Nurs. Inq. 3 (2), 101-111.

Robinson, W.S., 1950. Ecological correlations and the behavior of individuals. Am. Sociol. Rev. 15 (3), 351-357.

Rogers, M.E., 1980. Nursing: a science of unitary man. In: Riehl, J.P., Roy, C. (Eds.), Conceptual Models for Nursing Practice, second ed. Appleton-Century Crofts, New York.

Roy, C., 1976. Introduction to Nursing: an Adaptation Model. Prentice-Hall, New Jersey.

Rycroft-Malone, J., 2004. The PARIHS Framework-A framework for guiding the implementation of evidence-based practice. J. Nurs. Care Qual. 19 (4), 297-304.
Rycroft-Malone, J., Seers, K., Chandler, J., Hawkes, C.A., Crichton, N., Allen, C., Strunin, L., 2013. The role of evidence, context, and facilitation in an implementation trial: implications for the development of the PARIHS framework. Implement. Sci. 8 (1), 28.

Savage, J., 1997. Gestures of resistance: the nurse's body in contested space. Nurs. Inq. 4 (4), 237-245.

Schuster, E.A., Brown, C.L., 1994. Exploring Our Environmental Connections. Jones \& Bartlett Publishers.

Scott, J.G., Sochalski, J., Aiken, L., 1999. Review of magnet hospital research: findings and implications for professional nursing practice. J. Nurs. Adm. 29 (1), 9-19.

Selanders, L.C., 1998. The power of environmental adaptation florence Nightingale's original theory for nursing practice. J. Holist. Nurs. 16 (2), 247-263.

Seto-Nielsen, L.S., Angus, J.E., Gastaldo, D., Howell, D., Husain, A., 2013. Maintaining distance from a necessary intrusion: a postcolonial perspective on dying at home for Chinese immigrants in Toronto, Canada. Eur. J. Oncol. Nurs. 17 (5), 649-656.

Shattell, M.M., Andes, M., Thomas, S.P., 2008. How patients and nurses experience the acute care psychiatric environment. Nurs. Inq. 15 (3), 242-250.

Shreffler, J.M., 1996. An ecological view of the rural environment: levels of influence on access to health care. Adv. Nurs. Sci. 18 (4), 48-59.

Skott, C., Lundgren, S.M., 2009. Complexity and contradiction: home care in a multicultural area. Nurs. Inq. 16 (3), 223-231.

Solberg, S.M., Way, C., 2007. The importance of geography and health in nursing research. Can. J. Nurs. Res. 39 (3), 13-18.

Sweeney, N.M., de Peyster, I., 2005. Integrating environmental health into an undergraduate community health nursing course. Public Health Nurs. 22 (5), 439-444

Thomas, B.S.P., 2013a. The global phenomenon of urbanization and its effects on mental health. Issues Ment. Health Nurs. 34 (3), 139-140.

Thomas, E.A., 2013b. Place knowing of persons and populations restoring the place work of nursing. J. Holist. Nurs. 31 (4), 267-275.

Thorne, S., Canam, C., Dahinten, S., Hall, W., Henderson, A., Kirkham, S., 1998 Nursing's metaparadigm concepts: disimpacting the debates. J. Adv. Nurs. 27 (6), $1257-1268$.

Tourangeau, A.E., Widger, K., Cranley, L.A., Bookey-Bassett, S., Pachis, J., 2009. Work environments and staff responses to work environments in institutional long-term care. Health Care Manag. Rev. 34 (2), 171-181.

Upenieks, V., 2003. The interrelationship of organizational characteristics of magnet hospitals, nursing leadership and nursing job satisfaction. Health Care Manag. 22 (2), 83-98.

Vandemark, L.M., 2007. Promoting the sense of self, place, and belonging in displaced persons: the example of homelessness. Arch. Psychiatric Nurs. 21 (5), 241-248.

Vessey, J.A., DeMarco, R.F., Gaffney, D.A., Budin, W.C., 2009. Bullying of staff registered nurses in the workplace: a preliminary study for developing personal and organizational strategies for the transformation of hostile to healthy workplace environments. J. Prof. Nurs. 25 (5), 299-306.

Watty, K., White, M., Matthews, J., Buchanan, L., Clarke, J., Sulkowski, A., Toner, G., Rischin, D., 2003. There's no place like home: a prospective evaluation of chemotherapy in the home. Aust. J. Cancer Nurs. 4, 18-20.

West, E., Barron, D.N., 2005. Social and geographical boundaries around senior nurse and physician leaders: an application of social network analysis. Can. J. Nurs. Res. 37 (3), 132-149.

West, C., Palmer, L., Tier, T., 2000. No place like home: an antepartum program at British Columbia's Women's Hospital has shown that women with complications of pregnancy do better and save the system money when they are cared for at home. Can. Nurse 96, 32-34.

Williams, M., 2001. Critical care unit design: a nursing perspective. Crit. Care Nurs. Q. 24 (3), 35-42. 